\title{
Placental a-microglobulin-1 in cervicovaginal fluid and cervical length to predict preterm birth by Thai women with symptoms of labor
}

\author{
Saifon Chawanpaiboon ${ }^{1 * \oplus}$, Vitaya Titapant ${ }^{1 \oplus}$, Julaporn Pooliam ${ }^{2 \oplus}$
}

\section{Abstract}

Background: Presence of placental $\alpha$ microglobulin-1 (PAMG-1) in cervicovaginal fluid is a bedside test to predict preterm delivery.

Objective: To determine whether the accuracy of a positive PAMG-1 test result to predict preterm birth within 7 days and 14 days in our hospital setting can be improved by adding cervical length.

Methods: We recruited 180 pregnant women who attended the labor ward of Siriraj Hospital, Thailand, from 2016 to 2018 for this prospective observational study of diagnostic accuracy. We used data from 161 women who met inclusion criteria including symptoms of preterm labor between $20^{0 / 7}$ and $36^{6 / 7}$ weeks' gestation without ruptured membranes and with cervical dilatation $<3 \mathrm{~cm}$ and effacement $<80 \%$. Presence of PAMG-1 in cervicovaginal fluid was tested using a PartoSure kit, cervical length was measured by transvaginal ultrasound, and the time to spontaneous delivery was calculated.

Results: Pregnant women with labor pain who had cervical length $<30 \mathrm{~mm}(45 / 161 ; 28 \%)$ went into delivery within 7 days, and women with a cervical length $<15 \mathrm{~mm}(11 / 14 ; 79 \%)$ went into delivery within 7 days. When the PAMG-1 test result was positive and cervical length was $\leq 15 \mathrm{~mm}$, the positive predictive value (PPV) was $83 \%$; and when cervical length was $\leq 30 \mathrm{~mm}$ the PPV was $69 \%$. The optimal cut off from receiver operating characteristic curve analysis showed that a cervical length $<25 \mathrm{~mm}$ and PAMG-1 positive result has a PPV of $80 \%$ to predict preterm birth within 7 days and $90 \%$ within 14 days. The area under the curve $(95 \%$ confidence interval) for a positive PAMG-1 result and cervical length $\leq 25 \mathrm{~mm}$ to predict preterm birth $<7$ days was $0.61(0.50,0.73)$ and $<14$ days was $0.60(0.49,0.70)$.

Conclusions: Cervical length ranging 15-30 mm combined with a positive PAMG-1 test result has a high accuracy to predict imminent spontaneous delivery within 7 days by women with preterm labor and cervical dilatation $<3 \mathrm{~cm}$ in clinical practice.

Keywords: cervical length measurement; IGFBP1 protein, human; PAMG-1 protein, human; premature birth; term birth

Preterm or premature birth remains a major problem worldwide, and the trend of preterm birth has increased in many developed countries at least up to 2007 [1]. The World Health
Organization (WHO) defines preterm birth as all births before 37 completed weeks of gestation [2]. Short and long-term complications of prematurity are reported [3]. The statistical

\footnotetext{
*Correspondence to: Saifon Chawanpaiboon, Maternal Fetal Medicine Unit, Department of Obstetrics and Gynaecology, Faculty of Medicine, Siriraj Hospital, Mahidol University, Bangkok 10700, Thailand, email: saifon.cha@mahidol.ac.th

'Department of Obstetrics and Gynaecology, Faculty of Medicine, Siriraj Hospital, Mahidol University, Bangkok 10700, Thailand

${ }^{2}$ Office for Research and Development, Faculty of Medicine Siriraj Hospital, Mahidol University, Bangkok 10700, Thailand
}

Ә Open Access. ๑ 2021 Chawanpaiboon et al., published by Sciendo. (cc) BY-NC-ND This work is licensed under the Creative Commons Attribution NonCommercial-NoDerivatives 4.0 License. 
unit of the Department of Obstetrics and Gynecology at Siriraj Hospital has reported that the annual incidence of preterm births steadily increased from $9.4 \%$ in 2004 to $13.7 \%$ in 2010 [4]. The 2015 preterm birth rate for the USA (based on obstetric estimate of gestational age) was 9.63\% [5]. Spontaneous preterm birth in the UK occurs in $7 \%-12 \%$ of pregnancies before 37 weeks' gestation and in about $4 \%$ of pregnancies before 34 weeks' gestation [6]. In most developed countries, $60 \%-80 \%$ of neonatal mortality and $75 \%$ morbidity are from preterm birth [6]. There is support for steroid therapy to reduce respiratory morbidity [7-9] and tocolytic agents to inhibit uterine contraction and postpone delivery [7]. Corticosteroid treatment shows maximum benefit from $24 \mathrm{~h}$ after administration [8]. However, preterm birth is difficult to diagnose and this results in overtreatment of threatened preterm labor, which was modeled to have a high cost of 4,653 EUR per case in 2013 (USD 6,179; Federal Reserve Foreign Exchange Rate G.5A), at least in The Netherlands [10]. Several agents with different modes of action have been used to inhibit uterine contractility with a maximum time of 136 days in Germany [11]. In $50 \%-80 \%$ of pregnant women, preterm labor does not lead to preterm birth within 7 days and $50 \%-70 \%$ of women in this group who received a placebo gave birth close to term [12]. The sign of preterm labor alone has a false positive rate $>50 \%$ [13], which may lead to unnecessary hospital admission for preterm labor management.

Methods to predict spontaneous preterm birth include cervical examination for dilatation and length [14-16], and testing cervicovaginal fluid for fetal fibronectin $[6,10]$, prolactin [17], and phosphorylated insulin-like growth factor binding protein 1 (phIGFBP-1), also known as placental $\alpha$ microglobulin-1 (PAMG-1) [18, 19], are effective in excluding spontaneous preterm delivery within 7-14 days. An ideal predictor would be a test that identifies who would deliver within $48 \mathrm{~h}$ to 7 days with the purpose of guiding the rational use of antenatal corticosteroids and tocolytic agents, decreasing unnecessary admissions, and correcting triage of patients that need in utero transfer $[14,15]$.

PAMG-1 was initially referred to as a specific $\alpha-1$ globulin of the placenta $[20,21]$, then as phIGFBP-1 [19], and was first isolated from human amniotic fluid as reported by Petrunin et al. in 1976 (cited by reference 1 in [22]). PAMG-1 is found in the amniotic fluid, blood, and vaginal discharge of pregnant women $[18,23]$. The concentration of PAMG-1 is several thousand-fold higher in amniotic fluid than it is in cervicovaginal secretions [22]. Therefore, PAMG-1 is an important biomarker for premature rupture of the fetal membrane (PROM). Moreover, during uterine contractions, PAMG-1 passes through chorioamniotic pores in fetal membranes, and through microperforations from degradation of the extracellular matrix of fetal membranes, possibly as a result of the inflammatory processes of labor or infection [18, 22].

The predictive accuracy of PAMG-1 is similar to that of qualitative fetal fibronectin [21, 24, 25]. However, to our knowledge, only one study has shown PAMG-1 to have a higher positive predictive value (PPV) than fetal fibronectin for predicting preterm labor [24]. A systematic review and meta-analysis showed that PAMG-1 is highly predictive of preterm birth within 7-14 days of preterm labor [25].

Cervical length measurement in symptomatic women can be used to predict preterm labor to shorten hospital stay without compromising patient care [26]. Cervical length measurement, fetal fibronectin, and uterine contraction monitoring during pregnancy have been proposed to predict preterm delivery, but their practical beneficial remains uncertain $[16,26]$. A cervical length $>30 \mathrm{~mm}$ or a negative fibronectin obtained from a patient with possible preterm labor can avoid overdiagnosis and unnecessary treatment [27]. However, a woman with a cervical length $<25 \mathrm{~mm}$ has a 6-fold increased risk of preterm delivery [27]. Combining cervical length of 15-30 $\mathrm{mm}$ with fetal fibronectin testing to predict delivery by women with symptoms of preterm labor improved identification of women with a low risk to deliver spontaneously within 7 days [28]. A high negative predictive value (NPV), but low PPV, make fetal fibronectin a good test to exclude premature delivery, but not a good test to predict it [29]. For a subgroup of symptomatic patients with a cervical length 15-30 mm, the PPV of fetal fibronectin remains poor [28].

Currently used methods to predict preterm labor include cervical length measurement, and presence of cervicovaginal fetal fibronectin or PAMG-1 [14, 16]. However, the accuracy of PAMG-1 and fetal fibronectin to diagnose preterm labor within 7 days is not significantly different [30]. When cervical length of $15-30 \mathrm{~mm}$ is combined with a PAMG-1 test, the accuracy to predict imminent spontaneous delivery is better than that when combining cervical length and fetal fibronectin $[25,31,32]$. However, to date there is no data from Thailand for its use in clinical practice.

We hypothesized that a test of cervicovaginal fluid for PAMG-1 using a commercial kit combined with cervical length would provide better accuracy to predict preterm birth within 7-14 days of preterm labor than either method alone.

\section{Methods}

The present prospective observational study was approved by the Ethics Committee of the Siriraj Institutional Review Board (Si 625/2016) and was conducted in full compliance with international guidelines for human research protection 
including the principles outlined in the contemporary revision of the Declaration of Helsinki 1964 (World Medical Association) incorporating the most recent (2013) and earlier amendments, the Belmont Report, Council for International Organizations of Medical Sciences Guidelines, and the International Conference on Harmonization in Good Clinical Practice. We retrospectively registered the study in the Thai Clinical Trials Registry (TCTR20180703002), although we note this was an observational study. We used guidelines in the STARD 2015 list of essential items to ensure appropriate reporting of studies of diagnostic accuracy [33].

A sample of 163 pregnant women was needed based on the expected $85 \%$ sensitivity of the tool and an estimated $15 \%$ preterm in the study setting [4]. From March 2016 to September 2018, we recruited a total of 180 pregnant women in a consecutive series who attended the labor ward at Siriraj Hospital, a tertiary care, primary teaching hospital of the Faculty of Medicine, Mahidol University, with a capacity of $>2,000$ beds in Bangkok, Thailand. All participants provided their written informed consent before entering the study.

The included patients were those with a singleton pregnancy who had symptomatic painful uterine contraction every 4 times in 20 min or 8 times in 60 min with a cervical opening $<3 \mathrm{~cm}$, effacement $<80 \%$, and a gestational age from $20^{0 / 7}$ weeks to $36^{6 / 7}$ weeks without ruptured membranes.

Excluded patients were those who had received a digital examination, had bleeding per vagina, had abruption placentae, suspected placenta previa, had been exposed to tocolytic drugs, cervical cerclage, trauma, urinary tract infection, girls $<18$ years, and those with fetal anomaly.

All patients recruited underwent a full clinical examination by the attending physicians. This included collecting the sample for the PAMG-1 test, sterile speculum examination, transvaginal ultrasound, and digital examination. The sample for the PAMG-1 test was taken before the cervical examination. If cervical opening was $\geq 3 \mathrm{~cm}$, effacement $\geq 80 \%$, the patient was excluded from the study. Parameters recorded at presentation included cervical length, cervical dilatation, contraction frequency, cervical effacement, patient history, and PAMG-1 test result. Data regarding the gestational age of delivery, timing of delivery, neonatal Apgar score, and body weight and possible complication after delivery were also recorded.

\section{PAMG-1 test}

The PAMG-1 test was performed using a kit (PartoSure PTL time-to-delivery test; Parsagen Diagnostics, a Qiagen company), following the instructions from the manufacturer $[31,32]$. Before speculum examination, digital examination, or transvaginal ultrasound, a sterile vaginal swab was inserted into the vagina for $30 \mathrm{~s}$. The swab was then inserted into a vial with solvent for $30 \mathrm{~s}$ and agitated by rotating using the thumb and forefinger. The swab was then removed from the vial, and a test strip was inserted into the sample to allow migration along the membranes through capillary action. When two lines were visible, the result was interpreted as positive. Using another method, the test was interpreted after the test strip had been inserted into the sample vial for $5 \mathrm{~min}$. The positive and negative PAMG-1 results were determined by the presence of two lines or one line, respectively $[31,32]$. If no line was seen, the test was undetermined and the patient data were excluded from the study. The treatment of the patients was followed by a decision of the attending physician without concern for the PAMG-1 test results.

\section{Cervical length measurement by transvaginal ultrasound}

A cervical length measurement of $30 \mathrm{~mm}$ was used as cut-off point. A patient with a cervical length $>30 \mathrm{~mm}$, or a negative PAMG-1 test result, was not considered be at risk of imminent spontaneous delivery within 2 days, 7 days, or 14 days, and by contrast, those patients with a cervical length of $\leq 30 \mathrm{~mm}$, or a positive PAMG-1 test result, were considered to be at risk of imminent spontaneous delivery within 7 days or 14 days.

\section{Statistical analysis}

We estimated the sample size for adequate sensitivity and specificity with a $95 \%$ confidence interval (CI) and $15 \%$ error of detected sensitivity using in house software from Mahidol University, Bangkok, Thailand. All other statistical analyses were completed using PASW Statistics for Windows (version 18.0; SPSS). Data are expressed as mean \pm standard deviation (SD), median (range) for continuous variables, and frequency (percentages) for categorical variables. The diagnostic accuracy of PAMG-1, cervical length, and a combination of the 2 indicators for predicting preterm birth was assessed using receiver operating characteristic (ROC) curves and determining the area under the curve (AUC). The sensitivity, specificity, PPV, NPV, and accuracy with 95\% CI were calculated. 


\section{Results}

From the total of 180 pregnant patients recruited, 19 were excluded from the study because of indicated deliveries (10 patients), incomplete data for cervical assessment (5 patients), and loss to follow-up (4 patients). Therefore, we included 161 patients in the study (Figure 1). All 161 patients underwent a PAMG-1 test and cervical length measurement. Their mean age was 28.9 years with an average body weight of $65 \mathrm{~kg}$. Most of the patients were primigravid. Gestational age was calculated from ultrasound in about $43 \%$. Some 145 (91\%) patients went into spontaneous vaginal delivery; other deliveries were assisted or by cesarean section (Table 1).

Of the 161 symptomatic pregnant women with cervical length $\leq 30 \mathrm{~mm}, 34(21 \%)$ went into spontaneous delivery within 7 days and $11(7 \%)$ went into spontaneous delivery

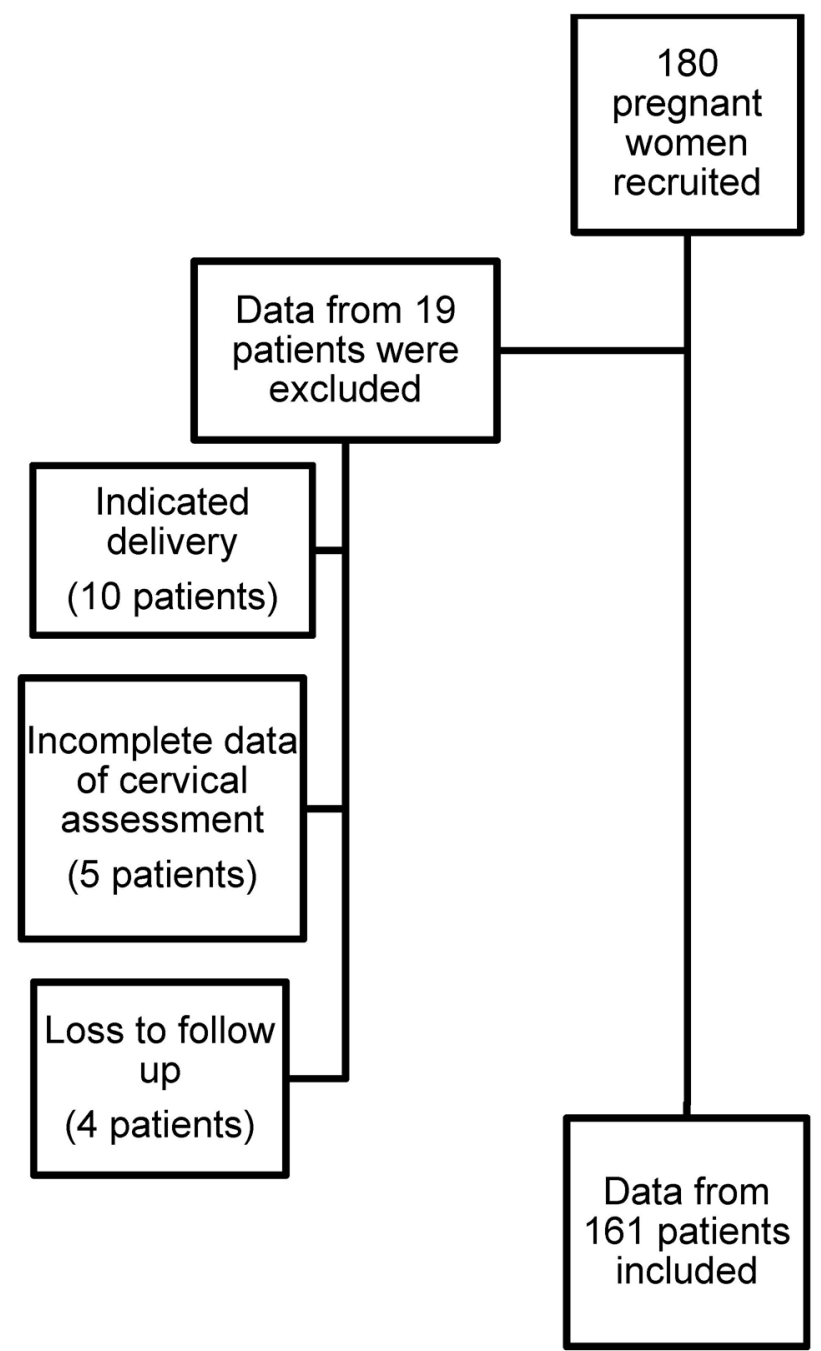

within 14 days (Table 2). Of the 14 symptomatic pregnant women with a cervical length $\leq 15 \mathrm{~mm}, 11$ (79\%) went into spontaneous delivery within 7 days (Table 3 ).

Table 1. Patient demographic characteristics

\begin{tabular}{lc}
\hline Demographic data & $\mathbf{n}=\mathbf{1 6 1}$ \\
\hline Maternal age (years) & $28.9 \pm 6.9$ \\
Body weight $(\mathrm{kg})$ & $65.0 \pm 12.5$ \\
Height $(\mathrm{cm})$ & $157.7 \pm 6.2$ \\
BMI $\left(\mathrm{kg} / \mathrm{m}^{2}\right)$ & $26.2 \pm 4.8$
\end{tabular}

Income (Thai baht per month)*

$20,000(0-70,000)$

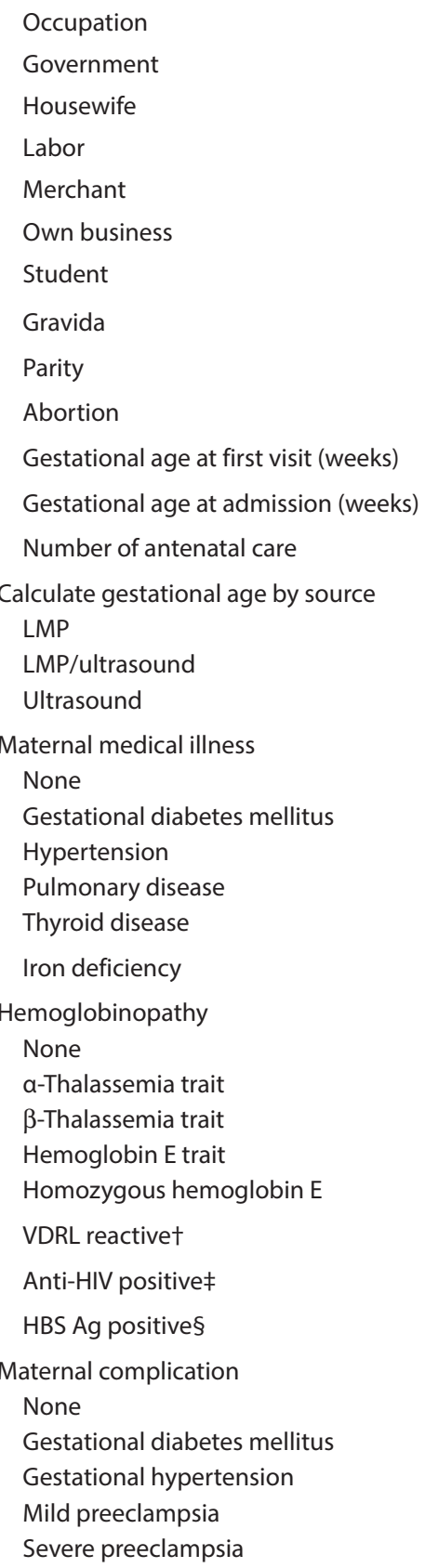

19 (12\%)

35 (22\%)

86 (53\%)

$11(7 \%)$

$4(3 \%)$

$6(4 \%)$

$1(1,6)$

$0(0,5)$

$0(0,3)$

$10(4,34)$

$33.2(21.1,36.3)$

$10(0,12)$

34 (21\%)

58 (36\%)

69 (42\%)

$144(89 \%)$

2 (1\%)

$3(2 \%)$

$5(3 \%)$

$7(4 \%)$

$13(8 \%)$

$121(75 \%)$

$8(5 \%)$

1 (1\%)

28 (17\%)

$3(2 \%)$

1 (1\%)

$2(1 \%)$

$25(16 \%)$

$137(85 \%)$

$11(7 \%)$

$5(3 \%)$

$2(1 \%)$

$6(4 \%)$ 
Table 1. Continued

\begin{tabular}{lc}
\hline Demographic data & $\mathbf{n}=\mathbf{1 6 1}$ \\
\hline Mode of delivery & \\
Cesarean section & $8(5 \%)$ \\
Spontaneous vaginal delivery & $147(91 \%)$ \\
Vacuum extraction & $6(4 \%)$ \\
\hline
\end{tabular}

Data are presented as $\mathrm{n}(\%)$, mean $\pm S D$, and median (range). *U.S. Federal Reserve Foreign Exchange Rate G.5A.1 USD = 35.26 (2016), 33.91 (2017), 32.30 (2018). Participants recruited March 2016 to September 2018. +VDRL reactive means positive screening test for syphilis.

fHBS Ag positive means positive screening test for antibodies to hepatitis B surface antigen.

$\S$ Anti-HIV positive means positive screening test for antibodies to HIV. $\mathrm{BMI}$, body mass index; HBS Ag, hepatitis B surface antigen; HIV, human immunodeficiency virus; LMP, last menstrual period; SD, standard deviation; VDRL, venereal disease research laboratory test. Some patients may have more than one type of thalassemia.

Table 2. Symptomatic patients with cervical length $<30 \mathrm{~mm}$ and delivery within 7 days and 14 days

\begin{tabular}{lc}
\hline All $\mathbf{1 6 1}$ patients included (symptomatic with cervical length $<\mathbf{3 0} \mathbf{~ m m}$ ) \\
\hline Delivery $<14$ days & $45(28 \%)$ \\
Delivery $<7$ days & $34(21 \%)$ \\
Delivery $7-14$ days & $11(7 \%)$ \\
Delivery $\geq 14$ days & $116(72 \%)$ \\
Total & $161(100 \%)$ \\
\hline
\end{tabular}

Table 3. Symptomatic patients with various cervical lengths and delivery within 7 days and 14 days

\begin{tabular}{lcc}
\hline $\begin{array}{l}\text { All symptomatic patients with } \\
\text { cervical length }<\mathbf{3 0 ~} \mathbf{~ m m}\end{array}$ & $\begin{array}{c}\text { Delivery } \\
<\mathbf{7} \text { days } \mathbf{n}(\%)\end{array}$ & $\begin{array}{c}\text { Delivery } \\
<\mathbf{1 4} \text { days } \mathbf{n}(\%)\end{array}$ \\
\hline Cervical length $<15 \mathrm{~mm}(\mathrm{n}=14)$ & $11(79)$ & $11(79)$ \\
Cervical length 15 to $30 \mathrm{~mm}(\mathrm{n}=50)$ & $14(28)$ & $18(36)$ \\
Cervical length $>30 \mathrm{~mm}(\mathrm{n}=97)$ & $9(9)$ & $16(16)$ \\
\hline
\end{tabular}

When PAMG-1 testing was combined with cervical length measurement $<30 \mathrm{~mm}$, the NPV was $83 \%$ to predict preterm birth within 7 days, and $77 \%$ to predict preterm birth within 14 days (Table 4). When PAMG-1 testing and cervical length measurement $\leq 15 \mathrm{~mm}$ was used, the PPV was $83 \%$ (Table 5). The optimal cut-off from ROC curve analysis shows that a cervical length $<25 \mathrm{~mm}$ and a PAMG-1 positive result has a PPV of $80 \%$ to predict preterm birth within 7 days and $90 \%$ to predict preterm birth within 14 days (Tables 6-8; Figures 2 and 3).

\section{Discussion}

We sought to determine whether testing cervicovaginal fluid for PAMG-1 could be used with cervical length to improve the predictability of preterm delivery within 7 days or 14 days in our hospital setting. The 161 patients in our present study were all treated with the same protocol, which did not affect the time to delivery. Of the 161 pregnant women with labor pain who had a cervical length $<30 \mathrm{~mm}, 45(28 \%)$ went into delivery within 7 days, and of those, 14 women with cervical length $<15 \mathrm{~mm}, 11$ (79\%) went into delivery in $<7$ days. A positive PAMG-1 test result had a high NPV of $82 \%$ for preterm birth within 7 days and $76 \%$ within 14 days. When a cervical length $<30 \mathrm{~mm}$ was combined with a PAMG-1 positive result, the NPV increased to $83 \%$ for preterm birth within 7 days, and $77 \%$ within 14 days. When a cervical length $<15 \mathrm{~mm}$ was combined with a PAMG-1 positive result, the PPV was higher than it was when using cervical length alone. Cervical length $<15 \mathrm{~mm}$ alone is a good predictor of preterm birth within both 7 days and 14 days and explains this finding [25]. Nikolova et al. [31] found that a positive PAMG-1 test result has a higher PPV than fetal fibronectin, or cervical length $<25 \mathrm{~mm}$. When

Table 4. Performance of a positive PAMG-1 test result and cervical length $<30 \mathrm{~mm}$ in symptomatic patients to predict preterm birth within 7 days and 14 days

\begin{tabular}{|c|c|c|c|c|c|c|c|c|}
\hline \multirow[t]{2}{*}{ Indicator } & \multicolumn{4}{|c|}{ Preterm birth $<7$ days } & \multicolumn{4}{|c|}{ Preterm birth $<14$ days } \\
\hline & Sensitivity (\%) & Specificity (\%) & PPV (\%) & NPV (\%) & Sensitivity & Specificity & PPV & NPV \\
\hline PAMG-1 & $10 / 34(29)$ & $112 / 127(88)$ & $10 / 25(40)$ & $112 / 136(82)$ & $12 / 45(27)$ & $103 / 116(89)$ & $12 / 25(48)$ & 103/136 (76) \\
\hline $95 \% \mathrm{Cl}$ & 15,48 & 81,93 & 21,61 & 75,88 & 15,42 & 82,94 & 28,69 & 68,83 \\
\hline Cervical length $<30 \mathrm{~mm}$ & $25 / 34(74)$ & $88 / 127(69)$ & 25/64 (39) & $88 / 97(91)$ & $29 / 45(64)$ & $81 / 116(70)$ & $29 / 64(45)$ & $81 / 97(84)$ \\
\hline $95 \% \mathrm{Cl}$ & 56,87 & 61,77 & 27,52 & 83,96 & 49,78 & 61,78 & 33,58 & 75,90 \\
\hline $\begin{array}{l}\text { PAMG-1 and cervical length } \\
<30 \mathrm{~mm}\end{array}$ & 9/34 (26) & $123 / 127(97)$ & $9 / 13(69)$ & $123 / 148(83)$ & $11 / 45(24)$ & $114 / 116(98)$ & $11 / 13(85)$ & $114 / 148(77)$ \\
\hline $95 \% \mathrm{Cl}$ & 13,44 & 92,99 & 39,91 & 76,89 & 13,40 & $94,>99$ & 55,98 & 69,83 \\
\hline $\begin{array}{l}\text { PAMG-1 or cervical length } \\
<30 \mathrm{~mm}\end{array}$ & 26/34 (77) & $77 / 127(61)$ & $26 / 76(34)$ & $77 / 85(91)$ & $30 / 45(67)$ & $70 / 116(60)$ & $30 / 76(40)$ & $70 / 85(82)$ \\
\hline $95 \% \mathrm{Cl}$ & 59,89 & 52,69 & 23,46 & 82,96 & 51,80 & 50,69 & 28,51 & 73,90 \\
\hline
\end{tabular}

$\mathrm{Cl}$, confidence interval; NPV, negative predictive value; PAMG-1, positive placental a microglobulin-1 test result; PPV, positive predictive value. 
Table 5. Performance of a positive PAMG-1 test result and cervical length $<15 \mathrm{~mm}$ in symptomatic patients to predict preterm birth within 7 days and 14 days

\begin{tabular}{|c|c|c|c|c|c|c|c|c|}
\hline \multirow[t]{2}{*}{ Indicator } & \multicolumn{4}{|c|}{ Preterm birth $<7$ days } & \multicolumn{4}{|c|}{ Preterm birth $<14$ days } \\
\hline & Sensitivity (\%) & Specificity (\%) & PPV (\%) & NPV (\%) & Sensitivity (\%) & Specificity (\%) & PPV (\%) & NPV (\%) \\
\hline PAMG-1 & $10 / 34(29)$ & $112 / 127(88)$ & $10 / 25(40)$ & $112 / 136(82)$ & $12 / 45(27)$ & 103/116 (89) & $12 / 25(48)$ & $103 / 136(76)$ \\
\hline $95 \% \mathrm{Cl}$ & 15,48 & 81,93 & 21,61 & 75,88 & 15,42 & 82,94 & 27,69 & 68,83 \\
\hline Cervical length $<15 \mathrm{~mm}$ & $12 / 34(35)$ & $122 / 127(96)$ & $12 / 17(71)$ & $122 / 144(85)$ & $12 / 45(27)$ & 111/116 (96) & $12 / 17(71)$ & $111 / 144(77)$ \\
\hline $95 \% \mathrm{Cl}$ & 20,54 & 91,99 & 44,90 & 78,90 & 15,42 & 90,99 & 44,90 & 69,83 \\
\hline $\begin{array}{l}\text { PAMG-1 and cervical length } \\
<15 \mathrm{~mm}\end{array}$ & $5 / 34(14)$ & $126 / 127$ (>99) & $5 / 6(83)$ & $126 / 155(81)$ & $5 / 45(11)$ & 115/116 (>99) & $5 / 6(83)$ & $115 / 155(74)$ \\
\hline $95 \% \mathrm{Cl}$ & 5,31 & $96,>99$ & $36,>99$ & 74,87 & 4,24 & $95,>99$ & $36,>99$ & 67,81 \\
\hline PAMG-1 or cervical length & $17 / 34(50)$ & $108 / 127(85)$ & $17 / 36(47)$ & $108 / 125(86)$ & $19 / 45(42)$ & $99 / 116(85)$ & $19 / 36(53)$ & $99 / 125(79)$ \\
\hline$<15 \mathrm{~mm} 95 \% \mathrm{Cl}$ & 32,68 & 78,91 & 30,65 & 79,92 & 28,58 & 78,91 & 36,70 & 71,86 \\
\hline
\end{tabular}

$\mathrm{Cl}$, confidence interval; NPV, negative predictive value; PAMG-1, positive placental a microglobulin-1 test result; PPV, positive predictive value.

Table 6. ROC curve analysis of a positive PAMG-1 test result and cervical length to predict preterm birth within 7 days and 14 days

\begin{tabular}{|c|c|c|c|c|c|c|c|c|}
\hline \multirow[t]{2}{*}{ Indicator } & \multicolumn{4}{|c|}{ Preterm birth $<7$ days } & \multicolumn{4}{|c|}{ Preterm birth $<14$ days } \\
\hline & Sensitivity (\%) & Specificity (\%) & PPV (\%) & NPV (\%) & Sensitivity (\%) & Specificity (\%) & PPV (\%) & NPV (\%) \\
\hline PAMG-1 & $10 / 34(29)$ & $112 / 127$ (88) & $10 / 25(40)$ & $112 / 136(82)$ & $12 / 45(27)$ & 103/116 (88) & $12 / 25(48)$ & $103 / 136(76)$ \\
\hline $95 \% \mathrm{Cl}$ & 15,48 & 81,93 & 21,61 & 75,88 & 15,42 & 82,94 & 28,69 & 68,83 \\
\hline Cervical length $<25 \mathrm{~mm}$ & $23 / 34(68)$ & $107 / 127(84)$ & $22 / 43(54)$ & $107 / 118(91)$ & $24 / 45(53)$ & $97 / 116(84)$ & $24 / 43(56)$ & $97 / 118(82)$ \\
\hline $95 \% \mathrm{Cl}$ & 50,83 & 77,90 & 38,69 & 84,95 & 38,68 & 76,90 & 40,71 & 74,89 \\
\hline $\begin{array}{l}\text { PAMG-1 and cervical length } \\
<25 \mathrm{~mm}\end{array}$ & 8/34 (24) & $125 / 127$ (98) & $8 / 10(80)$ & $125 / 151(83)$ & $9 / 45(20)$ & $115 / 116(>99)$ & $9 / 10(90)$ & $115 / 151(76)$ \\
\hline $95 \% \mathrm{Cl}$ & 11,41 & $94,>99$ & 44,98 & 76,88 & 10,35 & $95,>99$ & $56,>99$ & 69,83 \\
\hline $\begin{array}{l}\text { PAMG-1 or cervical length } \\
<25 \mathrm{~mm}\end{array}$ & $25 / 34(74)$ & $94 / 127(74)$ & $25 / 58(43)$ & 94/103 (91) & $27 / 45(60)$ & $85 / 116(73)$ & $27 / 58(47)$ & $85 / 103(83)$ \\
\hline $95 \% \mathrm{Cl}$ & 56,87 & 66,81 & 30,57 & 84,96 & 44,74 & 64,81 & 33,60 & 74,89 \\
\hline
\end{tabular}

$\mathrm{Cl}$, confidence interval; NPV, negative predictive value; PAMG-1, positive placental a microglobulin-1 test result; PPV, positive predictive value; $\mathrm{ROC}$, receiver operating characteristic.

Table 7. ROC curve analysis of cervical length $(<25 \mathrm{~mm})$ to predict preterm birth within 7 days and 14 days

\begin{tabular}{lcc} 
Measurement & $\begin{array}{c}\text { Preterm birth }<7 \text { days } \\
\text { Value }(\mathbf{9 5 \%} \mathrm{Cl})\end{array}$ & $\begin{array}{c}\text { Preterm birth }<\mathbf{1 4} \text { days } \\
\text { Value }(\mathbf{9 5 \%} \mathrm{Cl})\end{array}$ \\
\hline Area under curve & $0.78(0.68,0.88)$ & $0.73(0.64,0.82)$ \\
Sensitivity (\%) & $68(50,83)$ & $53(38,68)$ \\
Specificity (\%) & $84(77,90)$ & $84(76,90)$ \\
PPV (\%) & $54(38,69)$ & $56(40,71)$ \\
NPV (\%) & $91(84,95)$ & $82(74,89)$ \\
Accuracy (\%) & $81(74,87)$ & $75(68,82)$ \\
\hline
\end{tabular}

$\mathrm{Cl}$, confidence interval; NPV, negative predictive value; PPV, positive predictive value; ROC, receiver operating characteristic.

cervical length is used as an initial screen and later combined with PAMG-1 testing, it has the greatest utility to predict delivery within 7 days in patients with cervical length $15-35 \mathrm{~mm}$ $[31,32]$. Without cervical length screening, a positive PAMG-1
Table 8. AUC ( $95 \% \mathrm{Cl}$ ) for PAMG-1, cervical length $<25 \mathrm{~mm}$, PAMG-1 and cervical length $<25 \mathrm{~mm}$, and PAMG-1 or cervical length $<25 \mathrm{~mm}$

\begin{tabular}{lcc}
\hline Indicator & $\begin{array}{c}\text { Preterm birth } \\
<\mathbf{7} \text { days } \\
\text { AUC }(\mathbf{9 5} \% \mathrm{Cl})\end{array}$ & $\begin{array}{c}\text { Preterm birth } \\
<\mathbf{1 4} \text { days } \\
\text { AUC }(\mathbf{9 5} \% \mathrm{Cl})\end{array}$ \\
\hline PAMG-1 & $0.59(0.47,0.70)$ & $0.58(0.48,0.68)$ \\
Cervical length $<25 \mathrm{~mm}$ & $0.76(0.66,0.86)$ & $0.69(0.59,0.78)$ \\
PAMG-1 and cervical & $0.61(0.49,0.73)$ & $0.60(0.49,0.70)$ \\
length <25 mm & & \\
PAMG-1 or cervical length & $0.74(0.64,0.83)$ & $0.67(0.57,0.76)$ \\
$<25 \mathrm{~mm}$ & &
\end{tabular}

AUC, area under the receiver operating characteristic curve; $\mathrm{Cl}$, confidence interval; PAMG-1, positive placental a microglobulin-1 test result.

test result is more accurate than fetal fibronectin even when fetal fibronectin is combined with cervical length [31, 32]. The present study found combining a cervical length $<15 \mathrm{~mm}$ with a positive PAMG-1 test result was the best predictor for 


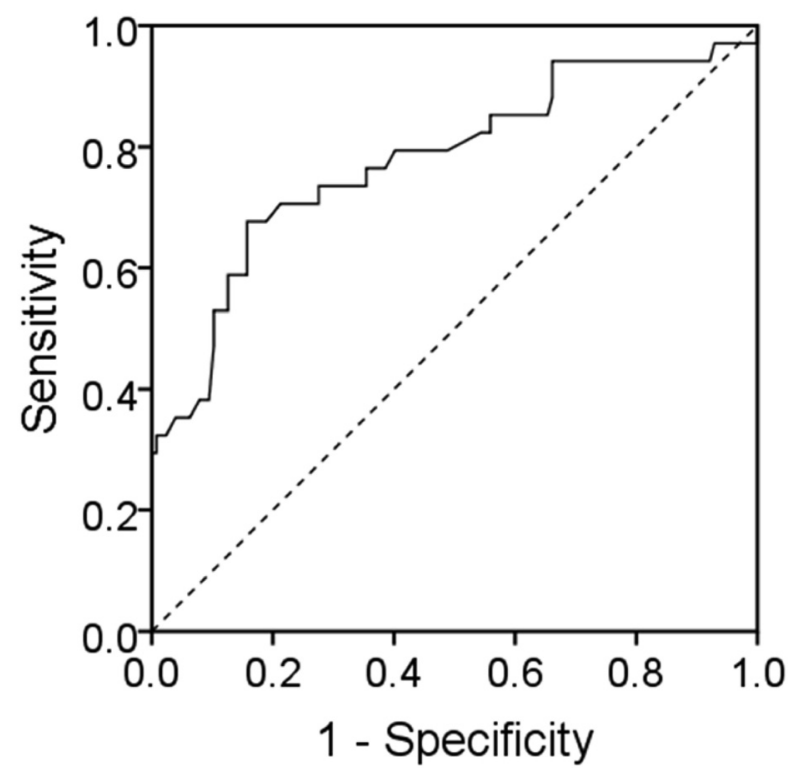

Figure 2. Receiver operating characteristic curve analysis of cervical length $<25 \mathrm{~mm}$ and a PAMG-1 positive result to predict preterm birth $\leq 7$ days. Diagonal segments are produced by ties. PAMG-1, placental a microglobulin-1.

delivery within 7 days in women with preterm labor. Combining the cervical length with the PAMG-1 test result increases the accuracy of the test to predict delivery within 7 days, achieving our goal of guiding the rational use of antenatal corticosteroids and tocolytic agents, decreasing unnecessary admissions, and correcting triage of patients that are need in of utero transfer [14, 15, 31, 32]. Therefore, the pregnant women who are not at risk of premature delivery can be advised to stay at home without unnecessary tocolytics or admissions. Patients who are at risk of premature delivery can be referred for tertiary care at specialized perinatal centers. The test allows physicians time to make the best decision to support their patients and manage them optimally. Psychological and physical burdens, the length of hospital stay, and health care costs can be reduced.

The lower cervical length cutoff point is associated with the highest specific prediction of imminent delivery within either 7 days or 14 days. A higher cervical length cutoff point lowers the specificity of the test. We sought to determine whether there is a specific cervical length range in which the PAMG-1 test would be most applicable and found that when a cervical length $\leq 15 \mathrm{~mm}$ was combined with a positive PAMG-1 result, 122/144 patients (85\%) delivered within 7 days. When cervical length $>30 \mathrm{~mm}$ was combined with a positive PAMG-1 result, 9/97 patients $(9 \%)$ delivered within 7 days. However, patients with cervical length measurements between these two cutoffs had varying rates of delivery within 7 days. In our present

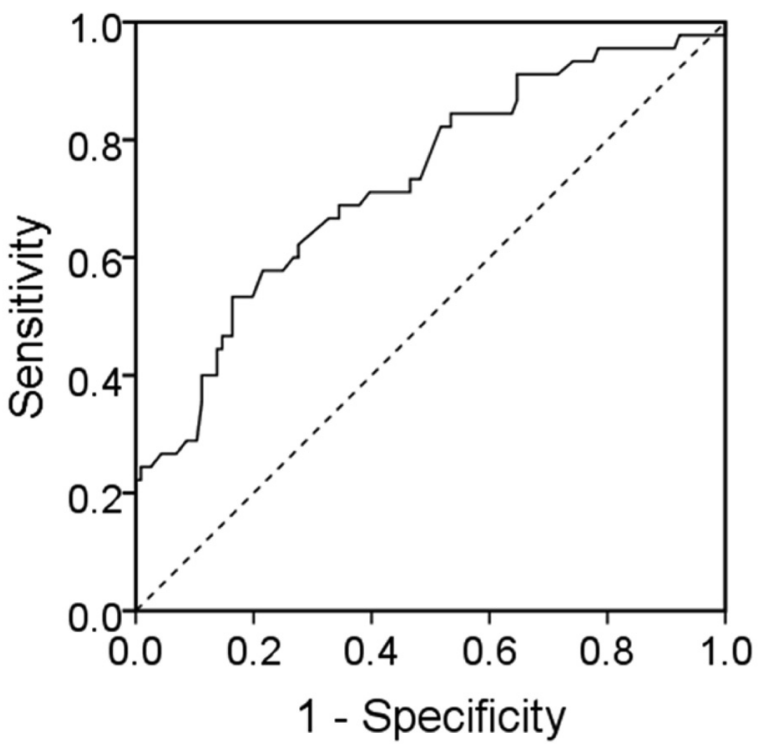

Figure 3. Receiver operating characteristic curve analysis of cervical length $<25 \mathrm{~mm}$ and a PAMG-1 positive result to predict preterm birth $\leq 14$ days. Diagonal segments are produced by ties. PAMG-1, placental a microglobulin-1.

study, 14/50 (28\%) patients with cervical length 15-30 mm delivered within 7 days of testing.

The present study suggests that a PAMG-1 test result is useful when combined with a cervical length of $15-30 \mathrm{~mm}$. The ROC curve analysis found that an optimal cut off of cervical length $<25 \mathrm{~mm}$ with a positive PAMG-1 result has a PPV of $80 \%$ to predict preterm birth within 7 days, and $90 \%$ within 14 days.

A limitation of the study is that patients with any bleeding per vagina, rupture of membranes, or who had undergone a vaginal examination had to be excluded. Therefore, the target population is not fully representative and the test can only be used in a limited population excluding those with the conditions described. Another limitation is that we did not meet our expected sample size target of 163 patients because of an unexpectedly high loss to follow up. Nevertheless, the sample size of 161 patients obtained did not unduly affect the results of the present study.

It is already known that a short cervix or cervical length $<15 \mathrm{~mm}$ is a good predictor of imminent spontaneous preterm delivery within 7 days. When cervical length measurement $15-30 \mathrm{~mm}$ was used as a cutoff, it was the least accurate predictor of imminent spontaneous preterm delivery within 7 days. This study adds that a cervical length $15-30 \mathrm{~mm}$ combined with a positive PAMG-1 test result will provide a higher predictor of imminent spontaneous preterm delivery within 7 days than either method alone, and should be considered for clinical practice. Our present findings support those of Nikolova et al. [31] and Bolotskikh and Borisova [32], who 
reported predictive results for a cervical length $15-35 \mathrm{~mm}$ combined with a positive PAMG-1 test result.

\section{Conclusion}

Cervical length 15-30 mm combined with testing cervicovaginal fluid for PAMG-1 has a high accuracy to predict imminent spontaneous delivery within 7 days by pregnant women with preterm labor and cervical dilatation $<3 \mathrm{~cm}$ in our clinical practice setting.

Author contributions. SC and VT contributed to the conception and design of the study, acquisition of data and its analysis and interpretation, drafting and critical revision of the manuscript. JP contributed to the conception and design of the study, analysis and interpretation of data, and critically revised the manuscript for important intellectual content. All authors approved of the final version submitted for publication and take responsibility for statements made in the published article.

Acknowledgments. We thank the Louis T. Leonowens (Thailand) Ltd., local representative in cooperation with Healthlink Europe (The Netherlands) as the authorized representative of the manufacturer, Parsagen Diagnostics, a Qiagen company, for providing the PartoSure PTL time-to-delivery (PAMG-1) test kits. We also thank Nattacha Palawat for her administrative support. We did not receive any other specific grant for this research from any funding agency in the public, commercial, or not-for-profit sectors.

Conflicts of interest statement. The authors have each completed the International Committee of Medical Journal Editors Form for Uniform Disclosure of Potential Conflicts of Interest. Julaporn Pooliam has no potential conflict of interest to disclose. Saifon Chawanpaiboon and Vitaya Titapant disclose the gift of the PartoSure test kits from the representatives of Parsagen Diagnostics (the manufacturer), but have no other financial relationship to disclose. The authors declare they had full access to all of the data in this study and take complete responsibility for the integrity of the data and the accuracy of the data analysis.

Data sharing statement. Statistical summaries of data generated and analyzed for the present report are included in this published article. Further details of data that support the findings of the present study are also available in figshare, with identifier https://doi.org/10.6084/m9.figshare.14751717; and all data are available on reasonable request for noncommercial purposes after deidentification from any patients whose data are included in this report.

\section{References}

[1] Schaaf JM, Mol BWJ, Abu-Hanna A, Ravelli ACJ. Trends in preterm birth: singleton and multiple pregnancies in the Netherlands, 2000-2007. BJOG. 2011; 118:1196-204.

[2] WHO: Recommended definitions, terminology and format for statistical tables related to the perinatal period and use of a new certificate for cause of perinatal deaths. Modifications recommended by FIGO as amended October 14, 1976. Acta Obstet Gynecol Scand. 1977; 56:247-53.

[3] Saigal S, Doyle LW. An overview of mortality and sequelae of preterm birth from infancy to adulthood. Lancet. 2008; 371(9608):261-9.

[4] Chawanpaiboon S, Kanokpongsakdi S. Preterm birth at Siriraj Hospital: a 9-year period review (2002-2010). Siriraj Med J. 2011; 63:143-6.

[5] Martin JA, Hamilton BE, Osterman MJK, Driscoll AK, Mathews TJ; Division of Vital Statistics. Births: final data for 2015. Natl Vital Stat Rep. 2017; 66:1-69. Hyattsville, MD: National Center for Health Statistics; 2017.

[6] Deshpande SN, van Asselt AD, Tomini F, Armstrong N, Allen A, Noake C, et al. Rapid fetal fibronectin testing to predict preterm birth in women with symptoms of premature labour: a systematic review and cost analysis. Health Technol Assess. 2013; 17:1-138.

[7] Hass DM. Preterm birth. BMJ Clin Evid. 2011; 2011:1404. PMCID: PMC3217816

[8] Roberts D, Dalziel S. Antenatal corticosteroids for accelerating fetal lung maturation for women at risk of preterm birth. Cochrane Database Syst Rev. 2006; (3): CD004454. doi: 10.1002/14651858. CD004454.pub2

[9] Antenatal Corticosteroids Revisited: Repeat Courses-National Institutes of Health Consensus Development Conference Statement, August 17-18, 2000 National Institutes of Health Consensus Development Panel. Obstet Gynecol. 2001; 98:144-50.

[10] van Baaren G-J, Vis JY, Grobman WA, Bossuyt PM, Opmeer BC, Mol BW. Cost-effectiveness analysis of cervical length measurement and fibronectin testing in women with threatened preterm labor. Am J Obstet Gynecol. 2013; 209:436.e1-8. doi: 10.1016/j.ajog.2013.06.029

[11] Weichert A, Weichert TM, Bergmann RL, Henrich W, Kalache $\mathrm{KD}$, Richter R, et al. Factors for preterm births in Germany - an analysis of representative German data (KiGGS). Geburtshilfe Frauenheilkd. 2015; 75:819-26.

[12] Nicholson WK, Frick KD, Powe NR. Economic burden of hospitalizations for preterm labor in the United States. Obstet Gynecol. 2000; 96:95-101.

[13] McPheeters ML, Miller WC, Hartmann KE, Savitz DA, Kaufman JS, Garrett JM, Thorp JM. The epidemiology of threatened preterm labor: a prospective cohort study. Am J Obstet Gynecol. 2005; 192:1325-9; discussion 9-30.

[14] American College of Obstetricians and Gynecologists; Committee on Practice Bulletins-Obstetrics. ACOG practice bulletin No. 171: Management of preterm labor. Obstet Gynecol. 2016; 128:e155-64. doi: 10.1097/AOG.0000000000001711

[15] Di Renzo GC, Roura LC, Facchinetti F, Antsaklis A, Breborowicz $\mathrm{G}$, Gratacos E, et al. Guidelines for the management of spontaneous preterm labor: identification of spontaneous preterm labor, diagnosis of preterm premature rupture of membranes, and 
preventive tools for preterm birth. J Matern Fetal Neonatal Med. 2011; 24:659-67.

[16] Oskovi Kaplan ZA, Ozgu-Erdinc AS. Prediction of preterm birth: maternal characteristics, ultrasound markers, and biomarkers: an updated overview. J Pregnancy. 2018; 2018:8367571. doi: $10.1155 / 2018 / 8367571$

[17] Buyukbayrak EE, Turan C, Unal O, Dansuk R, Cengizoğlu B. Diagnostic power of the vaginal washing-fluid prolactin assay as an alternative method for the diagnosis of premature rupture of membranes. J Matern Fetal Neonatal Med. 2004; 15:120-5.

[18] Lee SM, Romero R, Park JW, Kim SM, Park CW, Korzeniewski SJ, et al. The clinical significance of a positive Amnisure test in women with preterm labor and intact membranes. J Matern Fetal Neonatal Med. 2012; 25:1690-8.

[19] Ting H-S, Chin P-S, Yeo GSH, Kwek K. Comparison of bedside test kits for prediction of preterm delivery: phosphorylated insulin-like growth factor binding protein-1 (pIGFBP-1) test and fetal fibronectin test. Ann Acad Med Singapore. 2007; 36:399-402.

[20] Bohn, H., Kraus, W. Isolierung und charakterisierung eines neuen plazentaspezifischen proteins $\left(\mathrm{PP}_{12}\right)$ [Isolation and characterization of a new placenta specific protein $\left(\mathrm{PP}_{12}\right)$ ]. Arch Gynecol. 1980; 229:279-91. [in German, English abstract]

[21] Wing DA, Haeri S, Silber AC, Roth CK, Weiner CP, Echebiri NC, et al. Placental alpha microglobulin-1 compared with fetal fibronectin to predict preterm delivery in symptomatic women. Obstet Gynecol. 2017; 130:1183-91.

[22] Lee SM, Lee J, Seong HS, Lee SE, Park JS, Romero R, Yoon BH. The clinical significance of a positive Amnisure test in women with term labor with intact membranes. J Matern Fetal Neonatal Med. 2009; 22:305-10.

[23] Kobayashi K, Miwa H, Yasui M. Inflammatory mediators weaken the amniotic membrane barrier through disruption of tight junctions. J Physiol. 2010; 588(Pt 24):4859-69.

[24] Melchor JC, Navas H, Marcos M, Iza A, De Diego M, Rando D, et al. Predictive performance of PAMG-1 vs fFN test for risk of spontaneous preterm birth in symptomatic women attending an emergency obstetric unit: retrospective cohort study. Ultrasound Obstet Gynecol. 2018; 51:644-9.

[25] Pirjani R, Moini A, Almasi-Hashiani A, Farid Mojtahedi M, Vesali S, Hosseini L, Sepidarkish M. Placental alpha microglobulin-1 (PartoSure) test for the prediction of preterm birth: a systematic review and meta-analysis. J Matern Fetal Neonatal Med. 2019:1-13. doi: 10.1080/14767058.2019.1685962

[26] Sanin-Blair J, Palacio M, Delgado J, Figueras F, Coll O, Cabero L, et al. Impact of ultrasound cervical length assessment on duration of hospital stay in the clinical management of threatened preterm labor. Ultrasound Obstet Gynecol. 2004; 24:756-60.

[27] Iams JD. Prediction and early detection of preterm labor. Obstet Gynecol. 2003; 101:402-12.

[28] van Baaren GJ, Vis JY, Wilms FF, Oudijk MA, Kwee A, Porath MM, et al. Predictive value of cervical length measurement and fibronectin testing in threatened preterm labor. Obstet Gynecol. 2014; 123:1185-92.

[29] Revah A, Hannah ME, Sue-A-Quan AK. Fetal fibronectin as a predictor of preterm birth: an overview. Am J Perinatol. 1998; 15: 613-21.

[30] Çekmez Y, Kıran G, Haberal ET, Dizdar M. Use of cervicovaginal PAMG-1 protein as a predictor of delivery within seven days in pregnancies at risk of premature birth. BMC Pregnancy Childbirth. 2017; 17:246. doi: 10.1186/s12884-017-1427-0

[31] Nikolova T, Bayev O, Nikolova N, Di Renzo GC. Comparison of a novel test for placental alpha microglobulin-1 with fetal fibronectin and cervical length measurement for the prediction of imminent spontaneous preterm delivery in patients with threatened preterm labor. J Perinat Med. 2015; 43:395-402.

[32] Bolotskikh V, Borisova V. Combined value of placental alpha microglobulin-1 detection and cervical length via transvaginal ultrasound in the diagnosis of preterm labor in symptomatic patients. J Obstet Gynaecol Res. 2017; 43:1263-9.

[33] Bossuyt PM, Reitsma JB, Bruns DE, Gatsonis CA, Glasziou PP Irwig L, et al.; STARD Group. STARD 2015: an updated list of essential items for reporting diagnostic accuracy studies. Clin Chem. 2015; 61:1446-52. 